\title{
SOME ASPECTS REGARDING THE DISPLAY OF THE ORGANIZATIONAL ACTIVITY AT WORK OF THE LOGISTIC OFFICERS
}

\author{
Neno Hristov ${ }^{1^{\star}}$, Pavlin Glushkov ${ }^{2}$ \\ ${ }^{1}$ Colonel, Associate Professor, D.Sc., National Military Akademy "G.S.Rakovski", Sofia, Bulgaria, \\ ${ }^{2}$ Major, Ph.D., National Military University, Veliko Tarnovo, Bulgaria, pavlin_glushkov@mail.bg \\ ${ }^{*}$ Corresponding author
}

\begin{abstract}
Under modern circumstances high demands are put forward to the military professional management activity of the logistic officers. They are predetermined by the nature and character of the contemporary security environment and by the connected conflicts and crises, by the continuous development of the conceptual and doctrine understandings of warfare.

Subject of study is the military professional activity, while target of the research is the organization activity of the Logistic officers.

The aim of the research is by means of analyzing the military professional management activity and the specific features of the activity of the logistic officers to the outline the role and the display of their organization activity.
\end{abstract}

Keywords: military professional activity, organizational activity, managing functions

\section{INTRODUCTION}

The rapidly changing security environment, the development of warfare and of the civil-military relations put new demands to the organization activity of the Logistic officers.

The new political, economic and social realities require a timely reaction of the Logistic officers to the continuously changing circumstances during the process of implementation of their functional duties, require to take non-standard decisions under conditions of limited financial resources, to analyze the current situation in the absence of sufficient information and time resources and to plan and predict the influences and the consequences of the taken management decisions.

While performing his functional obligations, the Logistic officer has to evaluate the delegated task and the available resources and must organize in time the activity of the subordinated forces and assets. The specificity of the organization activity of the Logistic officers is reflected in the organization of cooperation with state authorities, with the business and with the non-governmental and further bodies. 


\section{SPECIFIC FEATURES OF THE MILITARY PROFESSIONAL ACTIVITY}

The implemented military professional activity of the Logistic officers in time of peace differs significantly from their military activity during military conflicts or in cases of missions in response to crises. Subject of the military activity is the enemy, his human force, military equipment and shelters and so on (Med, 2009a) (Med, 2009b, pp. 15-20). The main target of this activity in peace time is to secure the military units during their training for warfare and the preparation of the subordinated logistic units and, in the case of armed conflict, the logistic support in order to achieve victory over the enemy. The result of the activity in peace time is the achieving of the needed levels of capability and preparedness for military action, while in time of war is the achieving of victory over the enemy (Terziev and Nichev, 2017h, pp. 631-635).

The specific features of the military professional activity include a daily intensive activity, where danger is bound with a real threat to the life of the military personnel and with material losses. The specificity is determined by the fact, that it has an increased moral, psychical and mental strain. As significant features of the living activity of the military personnel appear the specific military environment, which comprises a training process with weapon, military equipment and hazardous materials and substances in changing conditions and within a socially limited background.

The military professional activity passes in a special social environment, in extremely complicated, rapidly changing and strained situations and requires well developed cognitive abilities and an emotional-volitional stability in the process of organizing the activity of the subordinated personnel.

The basic factors, which influence the organizational activity of the Logistic officers, can be unified into two groups: institutional and social. Institutional factors are the factors of the military organization, having influence on the personality of the military man, such as: organizational, social-mental, technological etc. (Terziev and Nichev, 2017a, pp. 627-630).

The social factors are the factors of the main spheres of display of the social life, where the military man is actively involved: socio-economical, of the family, socio-political, religious, cultural etc.

The institutional factors are accompanied by numerous situations-stressors, the specificity of which is determined by: the high range of regulation of the viable activity (Statutes, orders etc.) and respectively minimal opportunities for initiative and creativity; a special organization of the viable activity: unregulated working time, service performance not only at daytime, but also at night, etc; activity accompanied with life threat and extreme mental and physical stresses; a relative social isolation.

The viable activity of the service people takes place in the uniform and restricted environment of the military garrison; the service people feel a relative loneliness and at the same time a physical publicity; uncertainty of the operational situation (a lack of information about the temporal, spatial and conceptual features of the operational situation).

\section{SPECIFIC FEATURES OF THE ORGANIZATION ACTIVITY OF THE LOGISTIC OFFICERS}

Terziev and Nichev share the opinion, that in the contemporary conditions the main characteristic of the management activity of the Logistic officer is his ability to organize effectively the work of the subordinated logistic units and of the personnel in accordance with the continuously changing public, economic and social circumstances (Terziev and Nichev, 2017f, pp. 682-694) (Terziev and Nichev, 2017i, pp. 667-671).

The organization activity of the Logistic officer is predetermined by its purposes (Todorkov, 1998, p. 10). The Logistic officer draws up a plan of the activity, based on the regulating documents and orders of the military commanders, where the terms, forces, resources etc. needed for the implementation of the assigned and resultant tasks are being planned, also determines the obligations of the subordinate and his own participation in the whole complex and interconnected activity. Therefore, the establishing of appropriate conditions, needed for the preparation and implementation of a particular activity for the performance of tasks, assigned to the Logistic, is the purpose of the organizational activity of the Logistic officer. The orders, instructions, requirements of the superior command, the character of the forthcoming task, the preparation level of the subordinate officers, Sergeants, soldiers and civilian personnel affect the organizational activity of the Logistic officers.

Nichev and Terziev emphasize, that the sytem of goals is based on the relevant system of reasons, being formed as a result of the awareness of those goals, of the personal organizational abilities, of the acquired knowledge, skills and competences, connected with the organization activity (Terziev and Nichev, 2017b, pp. 915-919) (Terziev and Nichev, 2017c, pp. 659-670). 
The military group as a specific social system possesses a special integrative element - management unity, the institutional part of which manifests itself in a uniform managing authority, while the personality - in the principles of the single command (Todorkov, 1998, p. 82). The single command in the army, of the one part, is a principle, which lies at the basis of the organization activity of the Logistic officer, and of the other part, gives an opportunity to apply creativity into the work of the Logistic officer.

The organizational activity of the main part of the officers of the Bulgarian Army is restricted in the frames of the military community. This activity is a process of implementation of the military service tasks, studying the military equipment and weapon, doing military on-call works, preparation for combats against the enemy (Angelov, 1994, p. 11). The organizational activity of the Logistic officers is connected also with cooperation with the state authorities, non-governmental organizations, local authorities and different business structures.

\section{DISPLAY OF ORGANIZATIONAL ACTIVITY}

In the scientific literature, there is no unequivocal opinion about the concept „organizational activity“. Some of the researchers regard it as a compulsory part of the professional activity of each specialist (Terziev and Nichev, 2017d, pp. 695-706) (Terziev and Nichev, 2017e, pp. 646-658). Whereby such activity is being considered in two aspects: of the one part, as a basic professional activity and in this case the other activities of the specialist are subordinated to it, and of the other part, as an activity, equal to the further professional duties in the role of a link for the solving of various professional tasks. The other part of researchers considers that the organizational activity is function of the management process. The management process is not possible without the organizational activity, which is regarded either as a basis of each management activity, or as an independent sort of management activity in the system of management.

The analysis of the functional duties of the Logistic officers determines the main directions of display of the organizational activity within their military professional implementation:

- Organization of the training and of the performing the orders of the Commander of the Unit for logistic support. The single command principle in the Bulgarian Army and the principle for execution of the ordered tasks present a specific sphere of the military professional activity and seen in this light, the Logistic officer is simultaneously a direct performer and an organizer of the implementation of the order. In the light of the content, the organizational activity for the execution of the order comprises: an evaluation of the commander's decision and of the basic and resultant tasks; an evaluation of the needed forces and resources for the execution of the task; taking a decision, distribution of the tasks; giving commands to the subordinated; organizing the work of the subordinate needed for the execution of the given task; supervision over the implementation of the tasks; evaluation of the performed work and reporting to the Commander about the execution of the given task;

- Organization of the activity of the subordinated units, of the military personnel and the civilian staff and of the personnel from other units for the implementation of given by the Commander of the military unit common tasks;

- Organizing of the cooperation with local and state authorities, with company-suppliers, repairing and manufacturing companies, with non-governmental and further structures in case of concluded agreements for the supply of goods and services and for providing services, aimed to increase the prestige of the military profession, or for military-patriotic education of the population etc.;

- Organization of the cooperation between the personnel of the logistic military units and specialists from the civilian branch for the execution of common tasks;

- Organization of the professional training of the subordinated personnel.

A conclusion can be drawn from the performed analysis, that the organizational activity of the Logistic officer in the military units is more diversified and possesses a definite specificity, in comparison to the Commanders of the military units. The specificity of the organization activity can be found not only in its contents, but also in its implementation.

\section{SPECIFICITY OF THE ORGANIZATION ACTIVITY}

First of all, the command and the management of the activity of the Logistic units are assigned to the relevant Unit Commander, while the Logistic officers organize the implementation of his orders. Hence, the organization activity must be directed at the unconditional execution of the orders of the Military Commanders and must be implemented in strict compliance with the requirements of the laws in force, with the regulations, instruction etc. In order not to create a paradoxical situation, when the Commander's orders can't be executed, because of the set out in them infringements of the regulations, the organization activity of 
the Logistic officers must be set in direction to provide assistance to the Commander for taking a legitimate decision (Nichev, 2017, pp 399-404) (Terziev and Nichev, 2017g, pp. 846-850).

Secondly, the organization activity of the Logistic officer is clearly regulated by the legislation of the Armed Forces and by the relevant job description and for this reason, it's appropriate each innovation to be regarded as means of improvement of the activity, and not as a radical change.

Third, the activity of most of the officers in the Bulgarian Army and from the structures, directly subordinated to the Minister of Defense, is being restricted within the military environment, whereas the organization activity of the Logistic officer goes beyond these frames. In order to perform the biggest part of the assigned tasks the organization activity of the Logistic officer is closely connected with the activity of the local and state authorities, with managers of different companies, with representatives of different organizations etc.

Fourth, the organization activity of the Logistic officer is implemented in mixed teams, consisting of military personnel and civilian staff.

Fifth, in the light of the consistent part of the activity of the Logistic officer, his organization work is very versatile and has to cover material provisioning, exploitation of equipment, of armament and infrastructure, transport and movement, maintenance by the host country etc. This way, the organization activity of the Logistic officer comprises the joint organization of the work of many people in different spheres of the military life, the applying of special efforts to ensure the coherence and coordination of the activity of these people and to subject the results to the achievement of the main goal - logistic support of the military-training activity.

\section{GENERAL ARRANGEMENT OF THE RESEARCH}

The research work was carried out in different units of the Bulgarian Army in 2017. The research covered 42 officers, occupying different logistic positions of the tactical and operational management level.

The research was carried out at three stages: during the first stage the literature was studied and the questions were selected; at the second stage the research was carried out, where the empirical information was gathered with the help of a questionnaire in the form of direct group survey, and at the third stage the results obtained were being analyzed and conclusion were being drawn.

The examined logistic officers were asked the following questions: "Which manager's functions are of greatest importance in your work?" and "'Do you consider, that the organizing the activities of your subordinated structure is your most significant daily work?" In the same time they had to list the management functions according to the spent working time, needed for their implementation. The results of the conducted research demonstrate, that $55 \%$ of the examined put the management organizational function second before the management, i.e. before the taking of decisions and after the planning. The arrangement of the management functions according to their importance for the activity of the Logistic officers is illustrated in Diagram 1.

\section{Diagram 1: Arrangement of the management functions according to their importance for the activity} of the Logistic officers

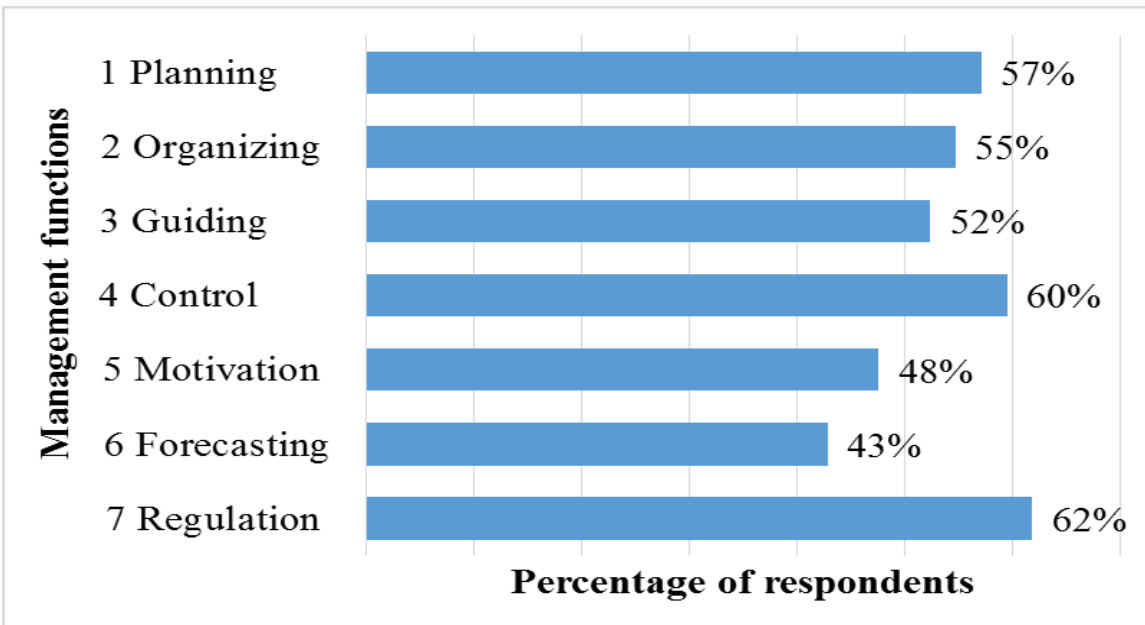

The responds of the examined officers of the tactical and operational management level demonstrate that more than the half $-52 \%$ of the examined logistic officers put the organization first. The control management 
functions are listed second; third comes the taking of decision (management) respectively with $48 \%$ and $43 \%$. The arrangement of the management duties according to the spent by the Logistic officers working time, needed for their implementation is illustrated in Diagram 2.

Diagram 2: Arrangement of the management duties according to the spent by the Logistic officers working time, needed for their implementation

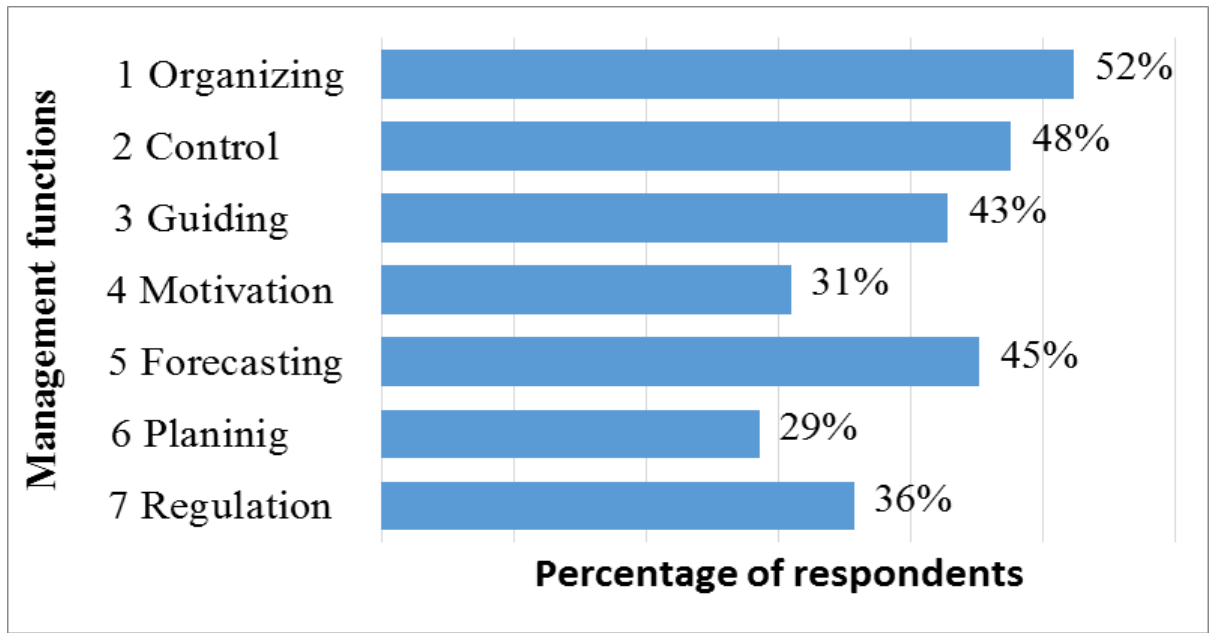

The results of the research illustrate, that the distribution of tasks, the grouping of these tasks, the allocation of tasks, the delegation of powers and the distribution of the resources, needed for the tasks, i.e. the organization is considered to be the most significant activity of the daily work of the Logistic officers by $73 \%$ of the examined. The results of the research are shown in Diagram 3.

\section{Diagram 3. Arrangement of organization duties in the daily work of logistics officers}

As a general regularity among all the examined appears the definition of the organization activities as a main function in the management work of the Logistic officers. Most probably it's due to the specificity of the military professional activity and due to the display of the organization work of the Logistic officers.

\section{CONCLUSION}

The performed analyses of the nature of the military professional activity and of the specific character of the organization work of the Logistic officers provide an appropriate basis in order to draw up the following conclusions:

1. The military professional activity of the Logistic officers occurs in a specific social environment and in versatile and quickly changing situations. It's characterized by the unconditional performance of the orders of the Commander and of the direct chief, resulting from the single command in the Army and by the legal regulation of the Statute of the Bulgarian Armed Forces and by the job description of the relevant position. 
2. The organization activity occupies a leading place in the structure of the management activity of the Logistic officers. This position is predetermined by the versatile character of the solved tasks during the implementation of their functional duties and is a necessary condition for a successful professional activity.

3. The organization activity of the Logistic officer comprises the joint organization of the work of many people form different spheres of the military and of the social life, also the special efforts, made for the organization of the logistic activities and the subordination of the results for the achievement of the main goal - logistic support of the daily work.

\section{REFERENCE LIST}

Angelov, Z. (1994). Psychological problems warrior activities. Publishing the Ministry of Defence "St. George", Sofia

Med, J. (2009a). Formation of readiness for organizational activity of the Future Logistic Officers: Monograph. "Scientific Book", Saratov, Russia.

Med, J. (2009b). Pedagogical formation of readiness of the future officers to organizational activities. Classical university education for the XXI century: the accessibility, efficiency, quality // Collection scientific works, Part 2. University Of Publishing Center "Science", Saratov, Russia, p. 15-20

Nichev, N. (2017). Research on the Preparation and Professional Realisation of Newly Appointed Logistics Officers. The 23rd International conference Knowledge-Based Organization, Volume XXIII No 2, pages 399-404

Terziev, V., Nichev, N. (2017a). Analysis of the Environment for Military Educational System Functioning and Its Impact on the Preparation of Cadets for Military Professional Activities in the Republic of Bulgaria. Proceedings of 4th International Conference on Education, Social Sciences and Humanities, 10-12 July 2017, OCERINT, Dubai, UAE, p. 627-630

Terziev, V., Nichev, N. (2017b). Developing the Readiness for the Organizational Activity of the Cadets. Central Bohemia University International Conference Proceedings 2017, Innovations in Science and Education, March 22-24, Published by Central Bohemia University, pages 915-919, http://dx.doi.org/10.12955/cbup.v5.1110, ISSN 1805-997X (Print), ISSN 1805-9961 (Online)

Terziev, V., Nichev, N. (2017c). Research of the motivation for management activities of cadets in the course of their military professional training. Proceedings of the VII International Academic Congress "Fundamental and Applied Studies in EU and CIS Countries" (United Kingdom, Cambridge, England, 26-28 February 2017), Volume VII. Cambridge University Press, pages 659-670

Terziev, V., Nichev, N. (2017d). Research of the motivation for management activities of cadets in the course of their military professional training. Language and Education, Issue 6 (2). Volume 31. Taylor \& Francis, 2017, Pages 695-706

Terziev, V., Nichev, N. (2017e). Research of the value orientation and structural peculiarities of management activities of cadets in the course of military professional training. Proceedings of the VII International Academic Congress "Fundamental and Applied Studies in EU and CIS Countries" (United Kingdom, Cambridge, England, 26-28 February 2017), Volume VII. Cambridge University Press, 2017, pages 646-658

Terziev, V., Nichev, N. (2017f). Research of the value orientation and structural peculiarities of management activities of cadets in the course of military professional training. Language and Education, Issue 6 (2). Volume 31. Taylor \& Francis, 2017, pages 682-694

Terziev, V., Nichev, N. (2017g). Research on the Management Skills and Abilities Acquired in the Military Education System. Central Bohemia University International Conference Proceedings 2017, Innovations in Science and Education, March 22-24, Published by Central Bohemia University, 2017, pages 846-850, http://dx.doi.org/10.12955/cbup.v5.1036, ISSN 1805-997X (Print), ISSN 1805-9961 
(Online)

Terziev, V., Nichev, N. (2017h). Some Aspects on Forming Preparedness of Logistics Military Officers for Management Activities. Proceedings of 4th International Conference on Education, Social Sciences and Humanities, 10-12 July 2017, OCERINT, Dubai, UAE, p. 631-635

Terziev, V., Nichev, N. (2017i). Streamlining Management Solutions for Economic, Effective and Efficient Spending of Resources for Security and Defense. Proceedings of 4th International Conference on Education, Social Sciences and Humanities, 10-12 July 2017, OCERINT, Dubai, UAE, p. 667-671

Todorkov, K. (1998). Psychological aspects of management of the commander. Publishing the Ministry of Defence "St. George", Sofia, 